\title{
Are Asian elephants afraid of honeybees? Experimental studies in northern Thailand
}

\author{
Shany Dror ${ }^{1,5} \cdot$ Franziska Harich $^{1,2}$. Orawan Duangphakdee ${ }^{3} \cdot$ Tommaso Savini $^{4} \cdot$ Ákos Pogány $^{5} \cdot$ John Roberts $^{6}$. \\ Jessica Geheran ${ }^{7} \cdot$ Anna C. Treydte $^{1,8}$
}

Received: 19 August 2019 / Accepted: 18 May 2020 / Published online: 9 June 2020

(c) The Author(s) 2020

\begin{abstract}
In many parts of South and Southeast Asia, rural farmers living at the borders of protected areas frequently encounter Asian elephants (Elephas maximus) raiding their crops and threatening farmers lives and livelihoods. Traditional deterrent methods often have limited success as elephants become habituated or alternate their movement and behavior. While African bees (Apis mellifera scutellate) have been shown to effectively and sustainably deter African elephants (Loxodonta africana) little is known about their Asian counterparts. We conducted two experiments to estimate the effectiveness of bees as an Asian elephant deterrent method. We analyzed the behavioral reaction of seven captive Asian elephants when confronted with a fence of A. mellifera hives blocking their way to a desired source of food. In addition, we explored the defensive reaction of five A. cerana hives and six A. mellifera hives to an artificial disturbance during both day and night time. The elephants crossed the beehive fence in $51 \%$ of the cases, the probability of crossing increased over time and the number of exposures had a significant effect on an elephant's crossing probability, indicating that elephants became habituated to the presence of the beehive fence. In the bee experiment, only one out of five A. cerana hives and one out of six A. mellifera hives reacted to the disturbance during the daytime, while during nighttime, none of them reacted defensively after being disturbed. We, therefore, conclude that neither A. mellifera nor A. cerana bees are likely to be effective in deterring wild Asian elephants from entering crop fields.
\end{abstract}

Keywords Crop raiding $\cdot$ Beehive defense reaction $\cdot$ Mitigation methods $\cdot$ Human-elephant conflict $\cdot$ Beehive fence

\section{Introduction}

In Asia, Human-Elephant Conflicts (HEC), as other human wildlife conflicts, are considered among the major conservation issues, leading to large financial annual losses as elephants destroy agricultural products and cause various human fatalities (Sukumar 2006). In consequence, cost-effective and efficient methods are needed to mitigate human-elephant conflicts. Traditional crop protection methods, such as scaring away elephants with firecrackers and

Handling editor: Sabine Begall.

Electronic supplementary material The online version of this article (https://doi.org/10.1007/s42991-020-00042-w) contains supplementary material, which is available to authorized users.

Shany Dror

shanymd@gmail.com

Extended author information available on the last page of the article loud noises are affordable but often lose their effectiveness as elephants become habituated (WWF 2008). High-voltage electrified fences are among the most effective mitigation methods (Sukumar 2003). However, due to their high construction and maintenance costs, they are mainly considered as long-term investment, especially for commercial perennial crops (Sukumar 2003) rather than a solution for smallscale farmers.

African honeybees (Apis mellifera scutellate) successfully deter African elephants (Loxodonta africana) from browsing on trees that are equipped with bee hives (Vollrath and Douglas-Hamilton 2002). While most of the elephant's body is covered with thick skin, there are some areas with thinner skin, such as the tip of the trunk, the ears and certain parts of the feet (Smith 1890) and it is likely that in these areas elephants are sensitive to pain (Shoshani et al. 2000). Consequently, African elephants avoid crossing fences, on which African beehives are hung ("beehive fences") (King et al. 2009, 2011). In addition, playbacks of disturbed 
African honey bees buzzing sounds caused elephants to run or walk away from their resting area (King et al. 2007). However, when repeatedly exposed to bee buzzing playbacks, elephants became habituated to the sound and their reaction decreased (King 2010). Generally, beehive fences can be easily incorporated into the ecosystem, because they require low investment and provide farmers with an additional source of income from selling the honey (Vollrath and Douglas-Hamilton 2002; King et al. 2009, 2011). While beehive fences seem to be an effective way to deter African elephants from croplands little is known about the interaction of the Asian counterparts, both bees and elephants. In Sri Lanka, Asian elephants (Elephas maximus) reacted by retreating from their resting area when exposed once to playbacks of disturbed Apis cerana hives (King et al. 2018). However, due to large differences between the habitats of the African and Asian elephants, this promising initial result reported by King et al. (2018) must be validated using live honeybees and replicated over time with other groups of Asian elephants.

In Thailand, A. cerana is the only native cavity nesting bee species (Wongsiri et al. 2000), while another widely distributed honey-cultivating bee species, A. mellifera, originates from Europe and is used for beekeeping (Wongsiri et al. 2000). The overall characteristics of the beehive defensive reaction are similar in most Apis species (Breed et al. 2004). The individual bee's defensive reaction involves flying towards the intruder, loud buzzing, and attacking through biting and stinging (Collins and Kubasek 1982). There is, however, large variation in the intensity and severity with which the different bee species respond (GuzmanNovoa and Page 1993; Breed et al. 2004). The African honey bee, A. mellifera scutellate Lepeletier, is a subspecies of the European honey bee A. mellifera. This species is known to be more excitable than other A. mellifera species (Michener 1975), reacting faster and in a more aggressive manner to introduced stimuli than the European A. mellifera species (Guzman-Novoa and Page 1993; Breed et al. 2004). No specific comparisons have been made between the defense reactions of the European A. mellifera and A. cerana. The studies conducted on A. mellifera thus far have tended to focus on the bees' defensive mechanisms without quantitively estimating their defensive reaction (Seeley and Seeley 1982).

The high aggression level of African bees is likely the reason for their success in deterring elephants (Vollrath and Douglas-Hamilton 2002). In addition, African bees are the only known bee species that can fly in low light levels (Theobald et al. 2006), which makes them especially suitable for deterring elephants, as most elephant crop raiding attempts occur during nighttime (Sukumar 1990).

It is yet unknown whether the defensive reaction of other honey bee species living in hives is sufficient to deter elephants. To answer this question, we tested both the defensive reaction of the bees as well as the elephants' response to the bees. We expected that A. mellifera and A. cerana would show very low aggression during nighttime and overall lower aggression levels than the African bees resulting in a lower deterrence effect on elephants. We used two experimental approaches, one including triggering aggressive responses from bees in beehives, and the other investigating the behavior of elephants towards beehive fences in Thailand.

\section{Methods}

\section{Experimental sites and species}

The beehive defensive reaction experiment Five $A$. cerana and six A. mellifera beehives were tested during the month of May, 2018 at the Ratchaburi Learning Park, Ratchaburi District, Thailand. Each hive was tested three times, twice a day, at 8:00 am (daytime experiments) and at 8:00 pm (nighttime experiments). The beehive population ranged from 1700 to 7550 bees for A. cerana hives and 3260 to 8030 bees for A. mellifera hives. Assessments of the hives' population was done by taking pictures of both sides of the hives' frames during night time and counting the number of bees that appeared in the pictures (similar to the method described by Collins and Kubasek 1982).

The elephants' reaction to beehives experiment: The reaction of seven captive Asian elephants to the presence of $A$. mellifera hives was tested. Hives of the species A. mellifera were chosen as they are easier to cultivate and produce larger quantities of honey (Verma 1991). The experiment was performed in a fenced area of the Golden Triangle Asian Elephant Foundation (GTAEF), Chiang Saen, Chiang Rai district, Thailand. The six female and one male elephant were between the ages of 26-50 years and were born and raised in captivity. The elephants were kept in a semi-natural surrounding and, according to their caretakers, were likely to have encountered bees in the past. The observations were carried out from June to July 2018, during the morning hours. This experiment received the ethical permission for conducting experiments on animals from the National Research Council of Thailand (NRCT) and was conducted under the NRCT's supervision.

\section{Experimental setup}

The beehive defensive reaction experiment The original experimental apparatus was designed according to the Beehive Fence Construction Manual (King 2014), where each beehive was hung between two poles. To mimic an elephant crossing the beehive fence the hive was pulled backwards through an additional rope and then released, causing it to swing back and forth. However, in pilot tests, this kind of 
stimulus did not increase the number of bees counted at the entrance of the hive and did not lead to a defensive reaction in either A. cerana or A. mellifera. Hence, the setup was modified. In the new setup the hive hung $1 \mathrm{~m}$ above the ground on a rope connected to a pulley. A researcher standing $4 \mathrm{~m}$ away from the hive pulled the rope, lifting the hive $1 \mathrm{~m}$, and then immediately dropped it (the process is referred to as stimulus-S) (P1 in the supplementary PDF). The stimulus was repeated five times $(\mathrm{S} 1, \mathrm{~S} 2, \ldots, \mathrm{S} 5)$ every $30 \mathrm{~s}$ to increase the bees' initially mild reaction.

The elephants' reaction to beehives experiment: The experiment was conducted in a rectangular enclosure of $70 \mathrm{~m} \times$ $12 \mathrm{~m}$, fenced by two electric wires, which were not activated during the experiment. Six out of the seven elephants did not show any avoidance behaviors towards the wires and touched or stepped over it if it blocked the elephants' way. One female elephant showed avoidance behavior towards the wires but was not afraid of standing in close proximity $(1 \mathrm{~m})$ to the fence. Inside the enclosure, $15 \mathrm{~m}$ from its rear end, a beehive fence was built hanging from three wooden frames of $2 \mathrm{~m}$ high and $1 \mathrm{~m}$ wide, $3 \mathrm{~m}$ apart from each other. The hive was connected to a pulley and a tripping wire, which was stretched between two poles of the enclosure's fence, $3 \mathrm{~m}$ in front of the wooden frames, at a height of $1.40 \mathrm{~m}$ above ground (Fig. 1, P4 in the supplementary PDF). When an elephant tried to cross the tripping wire, it broke, causing the beehives positioned in front to drop $1 \mathrm{~m}$ down (Fig. 1, supplementary video).

The elephants' behavior was examined in three different sessions:

Baseline treatment (BASELINE) In this treatment a bucket containing sunflower seeds, sugarcane, bananas or both sugarcane and bananas combined was placed at the end of the enclosure (see P5 in the supplementary PDF). The elephants were released one at a time into the enclosure and allowed to wander around freely for $20 \mathrm{~min}$. This session consisted of three trials conducted over three following days (one trial per day) for each elephant. At the end of the session all of the elephants exhibited a consistent behavior of entering the enclosure and walking to the other end to eat the food.

Beehive treatment (BEEHIVE) During this session, the beehive fence was in place and beehives were hanging from the wooden frames. Three buckets of food containing sunflower seeds were placed $3 \mathrm{~m}$ behind the wooden frames. In addition, bananas or sugarcane were placed close to the buckets (see P6 in the supplementary PDF). This session consisted of five trials, one trial per day, conducted over five consecutive days.

Dummy Beehive treatment (DUMMY): In this session the experimental setup and testing procedure were similar to

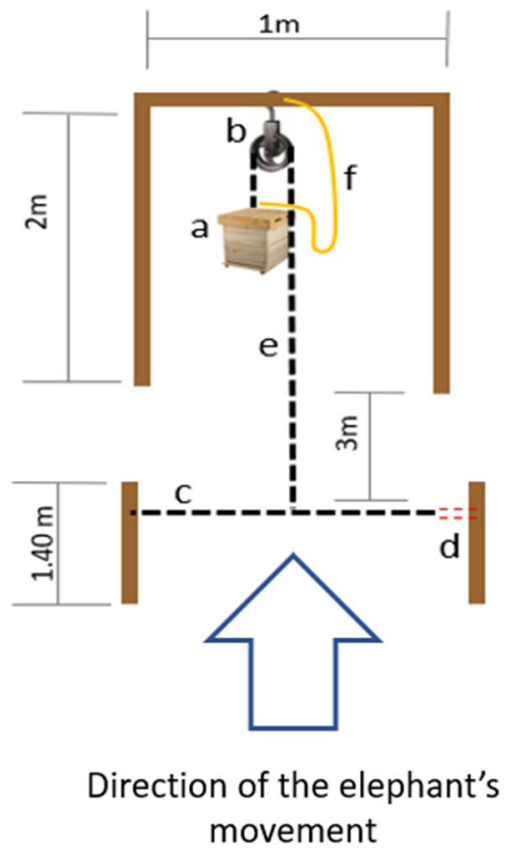

Fig. 1 Beehive fence design. (a) beehive, (b) pulley, (c) tripping wire, (d) weak piece of rope designed to break when the elephants pass over the tripping wire (c), (e) rope connecting hive to the tripping wire (c), (f) security rope preventing the hive from hitting the ground

BEEHIVE but the beehives were replaced with plastic buckets of similar dimensions to test if there was any learned or instinctual behavior that might result from the elephants' encounter with the structure of the beehive fence (see P7 in the supplementary PDF). This session consisted of five trials, one trial per day, conducted over five consecutive days.

As habituation can have a significant influence on the elephants' behavior, we used a crossover design. After the completion of BASELINE, the seven elephants were randomly divided into two groups and tested in a counterbalanced order. As the purpose of the baseline was to familiarize the elephants with the setup, we did not include this treatment in the analysis. The session number (first or second), therefore, refers to either the BEEHIVE or the DUMMY treatments, depending on the group, in which the elephant was tested.

\section{Data collection and analysis}

The beehive defensive reaction experiment The bees' defensive reaction was assessed by counting the number of bees crowding at the entrance of the hive in reaction to the stimuli. During daytime we took a video recording of the hive entrance (see supplementary video) and during nighttime we used an infrared camera, which was programmed to take a still photo of the hive entrance every $5 \mathrm{~s}$ (P2 and P3 in the supplementary PDF). The number of bees appearing at daytime and nighttime cameras was counted $10 \mathrm{~s}(t-10)$ 
and $5 \mathrm{~s}(t-5)$ before the first stimulus (these measurements were averaged and used as the first control), directly after the hive was dropped and stabilized ( $t 0)$, and then every $5 \mathrm{~s}$ until $150 \mathrm{~s}$ after the first stimulus $(t 5, t 10, t 15 \ldots t 150)$ as well as 5 min after the stimulus ( $t 300$, a measurement that was used as the second control). The number of bees reacting to the treatments is given in Table 1, where the number of bees counted during each of the stimuli and the three repeated trials of daytime and nighttime were averaged for each hive, separately.

We ran the analysis using two different approaches; in the first approach, time periods were kept separate, whereas in the second analysis, responses over time periods were averaged and the number of bees reacting is presented as the net reaction (the number of reacting bees minus the control count).

Statistical analysis was carried out using the R statistical environment (version 3.4.2; R Core Team 2017). Number of bees (response variable) was analyzed in linear mixed models (R package 'Ime4'; Bates et al. 2015) with species, daytime (day or night), time period, and all two-way and three-way interactions between these terms as fixed effects and hive ID as a random effect. In a stepwise model selection based on AIC values, we kept only those variables that had a significant effect.

The elephants' reaction to beehives experiment The average percentage of times the elephants crossed the beehive fence was calculated, first individually for each elephant by dividing the number of times it crossed the beehive fence by the number of times it was tested under each condition. Then the results of all elephants were combined and divided by the number of elephants in the experiment to calculate the mean. Data analysis was performed using the R statistical environment (version 3.4.2; R Core Team 2017). The probability of each elephant crossing the beehive fence was modelled with a generalized linear mixed model, assuming a binomial error distribution and logit link function (logistic regression) with experimental treatment (DUMMY, BEEHIVE) and the session number (first or second) as fixed effects, and the individual elephant nested within groups as a random effect.

In both experiments (bee and elephant) the effects of explanatory variables were analyzed by likelihood ratio tests (LRT); we provide $\chi^{2}$ and the corresponding $p$ values of LRTs of models including and excluding the given explanatory variable.

\section{Results}

The beehive defensive reaction experiment All the hives showed a very low defensive reaction during daytime and did not exhibit any defensive reaction during nighttime. Only one out of five A. cerana hives and one out of six A. mellifera hives reacted to the disturbance during the daytime, while during nighttime, none of them reacted defensively after being disturbed (Table 1). During daytime experiments, only two hives (C1 and M1) had more than an average of 50 bees crowding at the hive entrance after the stimuli were applied. These were also the only hives, for which the experimenters observed additional indications of the hives' defensive reaction such as loud buzzing and specific flight patterns (Collins and Kubasek 1982). During the nighttime experiments, all beehives that had more than 50 bees crowding at the entrance of the hive (hives C1, C5, and M1) showed lower numbers of bees after application of the stimuli compared to the control count (the number of bees counted prior to the application of the stimuli), indicating that there was no aggressive defensive reaction (Table 1; Table S1 in the supplementary material, $\mathrm{P} 2$ in the supplementary PDF).
Table 1 Overall bee population of each hive, the average number $( \pm \mathrm{SD})$ of bees that reacted during the daytime and nighttime tests and that of the control

\begin{tabular}{llcccr}
\hline Beehive & $\begin{array}{l}\text { Total beehive } \\
\text { population }\end{array}$ & Daytime test & Daytime control & Nighttime test & Nighttime control \\
\hline C1 & 7550 & $81.1 \pm 12.5$ & 11.8 & $91.7 \pm 10.8$ & 110.7 \\
C2 & 7118 & $2.6 \pm 0.5$ & 5.5 & $0.0 \pm 0.0$ & 0.0 \\
C3 & 2757 & $11.1 \pm 1$ & 10.7 & $0.7 \pm 0.1$ & 0.2 \\
C4 & 1355 & $11.3 \pm 1.1$ & 10.2 & $10.2 \pm 0.9$ & 8.7 \\
C5 & 1701 & $5.3 \pm 1.0$ & 3.2 & $73.9 \pm 13.4$ & 93.5 \\
M1 & 8028 & $79.6 \pm 10.3$ & 9.2 & $270.7 \pm 13.2$ & 287.2 \\
M2 & 6232 & $2.8 \pm 1.0$ & 1.2 & $1.2 \pm 0.2$ & 0.4 \\
M3 & 4023 & $1.8 \pm 0.5$ & 1.5 & $1.0 \pm 1.0$ & 1.5 \\
M4 & 4030 & $22.1 \pm 4.2$ & 1.2 & $0.4 \pm 0.1$ & 1.2 \\
M5 & 3258 & $21.0 \pm 6.5$ & 4.7 & $0.1 \pm 0.1$ & 0.0 \\
M6 & 3587 & $20.9 \pm 16$ & 9.5 & $17.8 \pm 2.25$ & 20.5 \\
\hline
\end{tabular}

The numbers of bees presented are an average of all measurements (repetitions and stimuli). C represents A. cerana hives and $\mathrm{M}$ represents $A$. mellifera hives. The raw data are supplied in the supplementary material 
Out of the different factors analyzed using the first approach, time periods had a significant effect on number of bees (LMM, effect of period: $\chi_{6}^{2}=13.692, p=0.033$; Fig. 2 ) that was driven by more bees being on the hive during stimulus than during control periods. In addition, daytime/nighttime had a species-specific effect, reflected in a significant two-way interaction (LMM of number of bees on hive, effect of daytime $\times$ species interaction: $\chi_{1}^{2}=6.066, p=0.014$ ). When using the second analysis approach, where time periods were averaged and the bees' reaction was presented in net values (see above), A. mellifera appears to have a stronger defensive reaction (Fig. 3, Table 2). However, there were no significant differences found between bee species or any of the other interacting factors (all $p>0.228$; Fig. 3, Table 2).
The elephants' reaction to beehives experiment The elephants crossed the beehive fence in $51 \%$ of the cases. The experimental treatment, DUMMY or BEEHIVE, did not have a significant effect on the crossing probability (Binomial GLMM of crossing, effect of experimental scenario, $\left.\chi_{1}^{2}=1.921, p=0.166\right)$. However, a Likelihood Ratio Test (LRT) found session number (first or second), to be the only factor with a significant influence on the crossing probability, with an increasing probability during the second session (Binomial GLMM of crossing, effect of session number, $\chi_{1}^{2}=4.663, p=0.031$; Table 3 , Fig. 4 ), suggesting that elephants got habituated to the experimental setup.
Fig. 2 Boxplots presenting a logarithmic scale of the number of A. mellifera bees (top) and A. cerana bees (bottom) that crowded at the entrance of the hive during daytime experiments (in white) and nighttime experiments (in gray). $\mathrm{C} 1$ is the control count conducted before the beginning of the experiment. $\mathrm{C} 2$ is the control count conducted 5 min after the application of the fifth stimuli
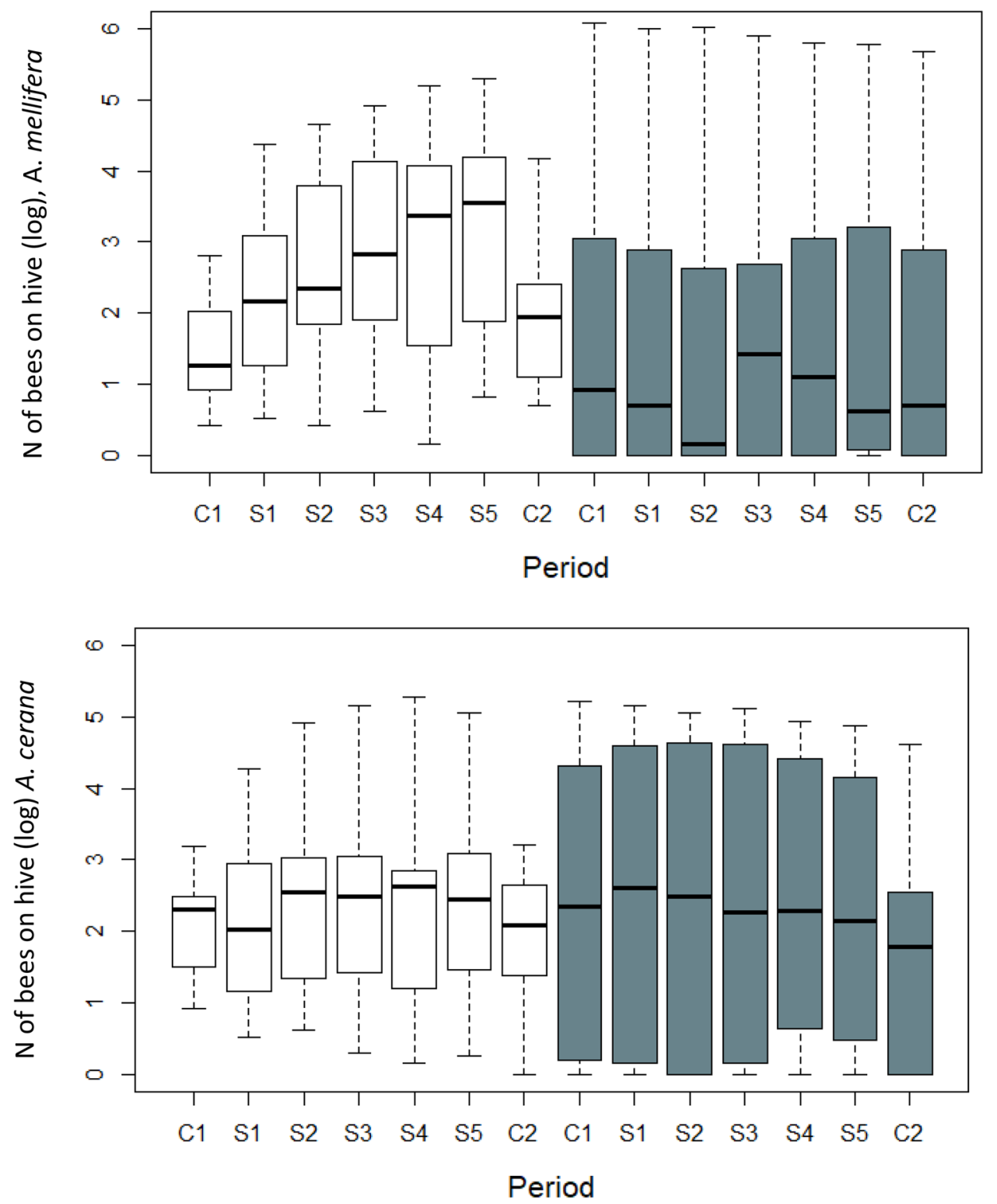


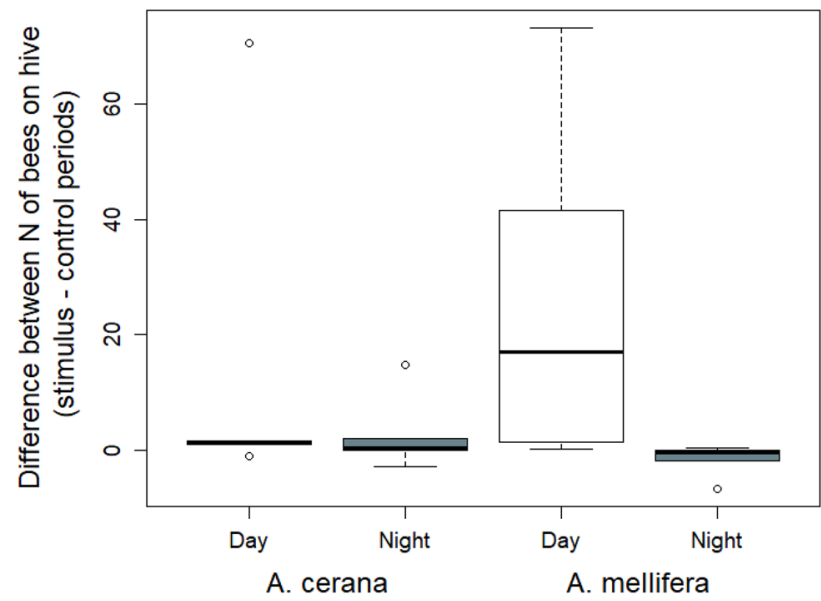

Fig. 3 Number of bees reacting during daytime and nighttime, with the five different time periods averaged for each specie, presented on a logarithmic scale and as the net reaction (average number of bees reacting to the stimulus minus average of the control measurements). No significant differences were found (all $p>0.228$ ). Negative values are a result of a decrease in the number of bees reacting compared to the control measurements

Table 2 Median values of the net number of bees that reacted (difference between the average number of bees reacting and the average number of the control counts)

\begin{tabular}{lrr}
\hline & Median & \multicolumn{1}{c}{ IQR } \\
\hline Day A. cerana & 1.276 & 0.669 \\
Night A. cerana & 0.364 & 2.067 \\
Day A. mellifera & 16.964 & 31.767 \\
Night A. mellifera & -0.384 & 1.399 \\
\hline
\end{tabular}

Negative values are a result of a decrease in the number of bees reacting compared to the control measurements

Table 3 Percentage of times in which each elephant crossed the beehive fence during the first and the second session

\begin{tabular}{llll}
\hline Elephant & Treatment order & $\begin{array}{l}\text { Crossing \% in } \\
\text { the 1st session }\end{array}$ & $\begin{array}{l}\text { Crossing \% in } \\
\text { the 2nd session }\end{array}$ \\
\hline $\mathrm{La}$ & Dummy/beehive & 60 & 100 \\
$\mathrm{Be}$ & Dummy/beehive & 20 & 0 \\
$\mathrm{Pr}$ & Dummy/beehive & 100 & 100 \\
$\mathrm{Ja}$ & Beehive/dummy & 0 & 0 \\
$\mathrm{Ri}$ & Beehive/dummy & 80 & 100 \\
$\mathrm{Bo}$ & Beehive/dummy & 20 & 60 \\
$\mathrm{Yu}$ & Beehive/dummy & 60 & 100 \\
$\mathrm{Crossing}$ average & & 49 & 66 \\
$\mathrm{SE}$ & & \pm 0.362 & \pm 0.472 \\
\hline
\end{tabular}

Elephants had a significantly higher chance of crossing the beehive fence during the 2nd session (Binomial GLMM, effect of session number, $\chi_{1}^{2}=4.663, p=0.031$ ), while the treatment did not have a significant effect on the crossing probability

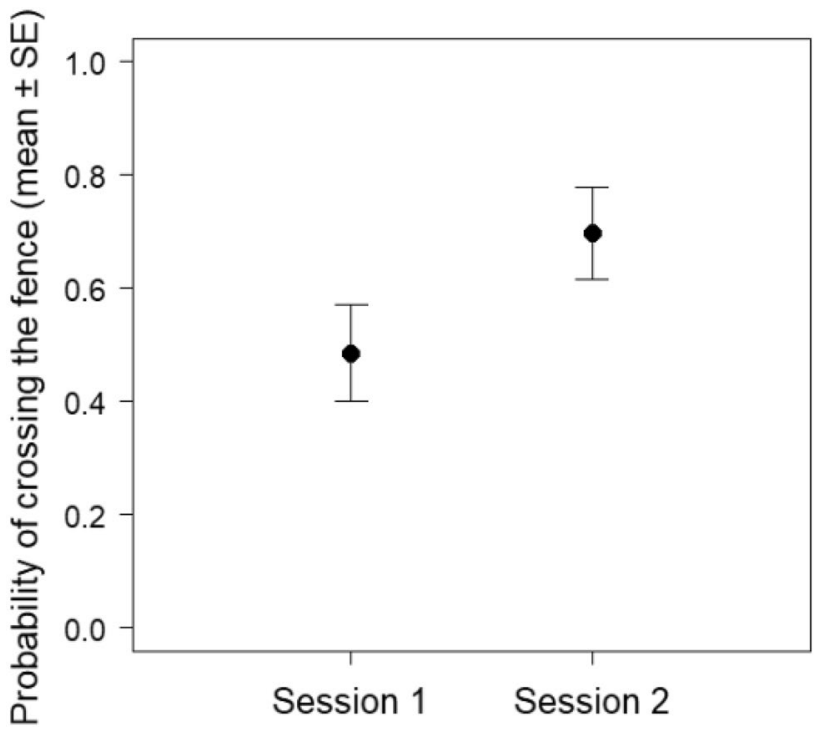

Fig. 4 Average percentage of times in which the elephants crossed the beehive fence according to the number of the session

\section{Discussion}

Based on the low numbers of bees counted at the hives' entrance in both A. mellifera and A. cerana hives we conclude that both species exhibited a very low aggressive defensive reaction during daytime and no aggressive reaction during nighttime. This finding explains why the probability of an elephant crossing the beehive fence was not influenced by the presence or absence of beehives but by the session number, which reflects the elephants' familiarization with the setup. We, therefore, stress that the tested captive Asian elephants were not deterred by A. mellifera bees and over time habituated to the presence of the beehive fence.

To the best of our knowledge, this study was the first attempt to quantify the defensive reaction of A. cerana. The numbers of both A. cerana and A. mellifera bees that crowded at the entrance of the hive as a response to the stimuli, were surprisingly low and indicated an almost nonexistent aggressive defensive reaction. While this finding contradicts those of previous studies of A. mellifera (Collins and Kubasek 1982; Breed et al. 2004) several studies indicate that a beehive's defensive reaction can vary strongly within different colonies of the same species (Balderrama et al. 1987; Guzman-Novoa and Page 1993; Breed et al. 2004). Beehives intended to serve as elephant deterrence methods should, therefore, be individually tested and selected based on their bees' aggression levels. A barrier designed to deter elephants must function as an entire unit, as elephants are known to find and breach through the weaker sections (WWF 2008). Therefore, beehive fences, even when occupied by relatively aggressive bees, might still not be a 
practical solution as elephants are likely able to identify the less aggressive hives.

During nighttime experiments both A. cerana and A. mellifera did not exhibit defensive reactions. This is not surprising as most honey bee species are diurnal and inactive during nighttime (Sauer et al. 2003). The European A. mellifera cannot forage at lower light intensities, while African bees can (Theobald et al. 2006). This may have a crucial impact on their ability to deter elephants, as crop raiding events occur mainly during nighttime (Sukumar 1990; King et al. 2010). We, therefore, decided for the elephant behavior experiment to hang A. mellifera hives on the beehive fence, as during daytime this species exhibited a slightly higher defensive reaction that increased over time. Additional economic factors played a role in selecting this species for our experiment, i.e., A. mellifera produces more honey and is easier to cultivate and manage (Verma 1991), while A. cerana has a high tendency to abscond when conditions are not favorable (Pokhrel et al. 2006). In fact, two of the six initial A. cerana hives that started this study absconded before and during the experiment.

In the Thai local press, beehive fences are occasionally recommended as a solution against Asian elephant crop raiding often asking readers to donate money for their construction (e.g., in the Bangkok Post: Mekloy 2020). However, we find this claim questionable as the efficacy of this solution has yet to be proven. In our experiment, in slightly more than half of the cases, elephants were willing to cross an occupied beehive fence to reach food. Contrary to findings of other studies (King et al. 2018), this indicates that Asian elephants did not exhibit any fear of honeybees. To our knowledge, our study is the first study investigating the relationship between Asian elephants and live honeybees in an experimental setup. We suggest that the increase in the probability, with which elephants crossed the beehive fence over time, is a result of both habituation as well as simple learning processes, both of which reflect the elephant's strong cognitive capacity and problem-solving skills (Rensch 1957).

Our results contradict findings of the only other published study conducted on Asian elephants and a non-African bee species thus far. King et al. (2018) played recordings of buzzing sounds produced by disturbed $A$. cerana hives to 120 wild elephants from 28 groups. In response to these recordings, the elephants moved further away from their resting places compared to control playback experiments. In addition, the elephants in the experiments of King et al. (2018) also vocalized more and presented more reassurance and investigative behaviors. In our experiments on defensive reactions of $A$. cerana and A. mellifera, the bees rarely produced a noticeable buzzing sound. As the bees' buzzing sound is known to deter elephants (King et al. 2007, 2018), the lack of this sound could also explain why the elephants in our study were not deterred by the presence of the beehives. An additional explanation for the elephants' behavior is the influence of habituation as demonstrated by the increasing probability, with which the elephants crossed the beehive fence over time. Habituation is a known problem in many elephant deterrence systems, especially in the case of noninvasive mitigation methods (WWF 2008). As we did not find any sting marks on the participating elephants during this study, the beehive deterrence method could be categorized as a noninvasive method. King (2018) exposed Asian elephants in Sri Lanka only once to the recordings of A. cerana but did not test the habituation over a longer time. In our study, the probability of the elephants crossing the beehive fence increased with the number of repetitions, meaning that the deterrence effect of the bees decreased as the elephants became habituated to their presence. Our findings correspond with those of a study conducted in Northern Kenya (King 2010), where playbacks of buzzing African bees were repeatedly played to African elephants who reacted less strongly as the number of times' they were exposed to the stimuli increased.

An important difference between our experiment and previous studies is that our experiment was conducted on captive elephants. Captive elephants were preferred in this study, because the forest vegetation in many parts of the Asian elephants' range makes it very difficult to observe the behavior of wild elephants. All elephants that participated in the experiment were in good physiological condition and were regularly supplied with adequate forage. We, therefore, assume that wild elephants lacking such easily available food supplies, might be even more motivated to cross beehive fences to reach desirable food sources. Although the capacity of this study to predict the reaction of wild elephants to beehive fences is limited, it is a crucial step in understanding the possible limitations of using beehive fences in Asia. Our study is the first of its kind, using both controlled experiments on live elephants and live bees.

During our observations, we tried to identify investigative and reassurance behaviors described by King et al. (2007, 2018). The elephants we studied rarely exhibited these behaviors and we conclude, therefore, that they were not disturbed by the presence of the bees. However, while King (2018) studied the reaction of family herds we studied the reaction of individual non-related elephants, a fact that might have influenced their communicative behaviors.

Both the small sample size of this experiment and the fact that it was conducted on captive elephants may limit the generality of the results. However, as the findings of this study are unambiguous, and the low aggression levels exhibited by the bees correspond with the elephants' unresponsive reaction, we find it unlikely that $A$. mellifera bees could serve as an effective means for deterring Asian elephants. 
Acknowledgements Open Access funding provided by Projekt DEAL. We thank the National Research Council of Thailand (NRCT) for granting the permits and permission to conduct this work. Funding was gratefully received from the Kayah Ecology foundation. We would like to express our gratitude to the Golden Triangle Asian Elephant Foundation for the participation of their elephants in this experiment. ÁP was supported by the UNKP-19-4 New National Excellence Program of the Ministry of Innovation and Technology, Hungary and by the János Bolyai Research Scholarship of the Hungarian Academy of Sciences.

\section{Compliance with ethical standards}

Conflict of interest There are no known conflicts of interest.

Ethical standards This publication and there has been no significant financial support for this work that could have influenced its outcome.

Open Access This article is licensed under a Creative Commons Attribution 4.0 International License, which permits use, sharing, adaptation, distribution and reproduction in any medium or format, as long as you give appropriate credit to the original author(s) and the source, provide a link to the Creative Commons licence, and indicate if changes were made. The images or other third party material in this article are included in the article's Creative Commons licence, unless indicated otherwise in a credit line to the material. If material is not included in the article's Creative Commons licence and your intended use is not permitted by statutory regulation or exceeds the permitted use, you will need to obtain permission directly from the copyright holder. To view a copy of this licence, visit http://creativecommons.org/licenses/by/4.0/.

\section{References}

Balderrama N, Diaz H, Sequeda A, Nunez J, Maldonado H (1987) Behavioral and pharmacological analysis of the stinging response in Africanized and Italian bees. In: Neuro Behav Honeybees, pp 121-128. https://doi.org/10.1007/978-3-642-71496-2

Bates D, Maechler M, Bolker B, Walker S (2015) Fitting linear mixedeffects models using lme4. J Stat Softw 67:1-48

Breed MD, Guzman-Novoa E, Hunt GJ (2004) Defensive behavior of honey bees: organization, genetics, and comparisons with other bees. Annu Rev Entomol 49:271-298. https://doi.org/10.1146/ annurev.ento.49.061802.123155

Collins AM, Kubasek KJ (1982) Field test of honey bee (Hymenoptera: Apidae) colony defensive behavior. Ann Entomol Soc Am 75:383-387. https://doi.org/10.1093/aesa/75.4.383

Guzman-Novoa E, Page RE (1993) Backcrossing Africanized honey bee queens to European drones reduces colony defensive behavior. Entomol Soc Am 86:352-355

King LE (2010) The interaction between the African elephant (Loxodonta africana africana) and the African honey bee (Apis mellifera scutellata) and its potential application as an elephant deterrent, vol 4. University of Oxford, Oxford, pp 60-83

King LE (2014) Beehive fence construction manual, 3rd edn, the elephants and bees project save the elephants. The elephants and bees project, save the elephants, Nairobi 00200, Kenya

King LE, Douglas-Hamilton I, Vollrath F (2007) African elephants run from the sound of disturbed bees. Curr Biol 17:832-833. https:// doi.org/10.1016/j.cub.2007.07.038

King LE, Lawrence A, Douglas-Hamilton I, Vollrath F (2009) Beehive fence deters crop-raiding elephants. Afr J Ecol 47:131-137. https ://doi.org/10.1111/j.1365-2028.2009.01114.x
King LE, Soltis J, Douglas-Hamilton I, Savage A, Vollrath F (2010) Bee threat elicits alarm call in African elephants. PLoS One. https ://doi.org/10.1371/journal.pone.0010346

King LE, Douglas-Hamilton I, Vollrath F (2011) Beehive fences as effective deterrents for crop-raiding elephants: field trials in northern Kenya. Afr J Ecol 49:431-439. https://doi.org/10.111 1/j.1365-2028.2011.01275.x

King L, Pardo M, Weerathunga S, Kumara TV, Jayasena N, Soltis J, de Silva S (2018) Wild Sri Lankan elephants retreat from the sound of disturbed Asian honey bees. Curr Biol 28:R64-R65. https:// doi.org/10.1016/j.cub.2017.12.018

Mekloy P (2020) Bees can help solve a jumbo problem. Bangkok Post, [online]. https://www.bangkokpost.com/life/social-and-lifes tyle/1831164/bees-can-help-solve-a-jumbo-problem. Accessed 30 Apr 2020

Michener CD (1975) The Brazilian bee problem. Annu Rev Entomol 20:399-416

Pokhrel S, Thapa RB, Neupane FP, Shrestha SM (2006) Absconding behavior and management of Apis cerana F. Honeybee in Chitwan, Nepal. J Inst Agric Anim Sci 27:77-86

R Core Team (2017) R: a language and environment for statistical computing. R Foundation for Statistical Computing, Vienna. https ://www.R-project.org/

Rensch B (1957) The Intelligence of elephants. Sci Am 196:44-49

Sauer S, Kinkelin M, Herrmann E, Kaiser W (2003) The dynamics of sleep-like behaviour in honey bees. J Comp Physiol A 189:599607. https://doi.org/10.1007/s00359-003-0436-9

Seeley TD, Seeley RH (1982) Colony defense strategies of the honey bees in Thailand. Ecol Monogr 52:43-63

Shoshani J, Rasmussen LEL, Kupsky WJ, Agnew DW, Borszcz GS (2000) Do elephants feel pain and if so, how do we know this? Elephant 2:48-52

Smith F (1890) Histology of the skin of the elephant. J Anat Physiol 24:493-503

Sukumar R (1990) Ecology of the Asian elephant in southern India. II. Feeding habits and crop raiding patterns. J Trop Ecol 6:33-53

Sukumar R (2003) The living elephants: evolutionary ecology, behavior, and conservation, vol 9. Oxford University Press, New York, pp 363-372

Sukumar R (2006) A brief review of the status, distribution and biology of wild Asian elephants. Zool Soc Lond 40:1-8. https://doi.org/1 0.1111/j.1748-1090.2006.00001.x

Theobald JC, Greiner B, Wcislo WT, Warrant EJ (2006) Visual summation in night-flying sweat bees: a theoretical study. Vis Res 46:2298-2309. https://doi.org/10.1016/j.visres.2006.01.002

Verma L (1991) Beekeeping in integrated mountain development. Oxford \& IBH Publ, New Delhi, p 237

Vollrath F, Douglas-Hamilton I (2002) African bees to control African elephants. Naturwissenschaften 89:508-511. https://doi. org/10.1007/s00114-002-0375-2

Wongsiri S, Chanchao C, Deowanish S, Aemprapa S, Chaiyawong T, Petersen S, Leepitakrat S (2000) Honey bee diversity and beekeeping in Thailand. Bee World 81:20-29. https://doi. org/10.1080/0005772X.2000.11099464

World Wide Fund for Nature (WWF) (2008) Review of human-elephant conflict mitigation measures practiced in South Asia, World Wide Fund for Nature. p 1-2. http://awsassets.panda.org/downl oads/review_of_human_elephant_final_reduced_01.pdf

Publisher's Note Springer Nature remains neutral with regard to jurisdictional claims in published maps and institutional affiliations. 


\section{Affiliations}

\section{Shany Dror ${ }^{1,5} \cdot$ Franziska Harich $^{1,2} \cdot$ Orawan Duangphakdee $^{3} \cdot$ Tommaso Savini $^{4} \cdot$ Ákos Pogány $^{5} \cdot$ John Roberts $^{6}$. Jessica Geheran ${ }^{7} \cdot$ Anna C. Treydte ${ }^{1,8}$}

Franziska Harich

f.harich@gmx.de

Orawan Duangphakdee

orawan.dua@mail.kmutt.ac.th

Tommaso Savini

tommasosavini@gmail.com

Ákos Pogány

akos.pogany@ttk.elte.hu

John Roberts

jroberts@anantara.com

Jessica Geheran

jgeheran@wcs.org

Anna C. Treydte

anna.treydte@nm-aist.ac.tz

1 Agroecology in the Tropics and Subtropics, University of Hohenheim, 70599 Stuttgart, Germany

2 Center for Nature Conservation Schopflocher Alb, Vogelloch 1, 73252 Lenningen-Schopfloch, Germany
3 King Mongkut's University of Technology Thonburi, Ratchaburi Campus, Rang Bua Chom Bueng, Ratchaburi 70150, Thailand

4 Conservation Ecology Program, Thonburi School of Bioresources and Technology, King Mongkut's University of Technology, Thakham, Bangkhuntien, Bangkok 10150, Thailand

5 Department of Ethology, Eötvös Loránd University (ELTE), Pázmány Péter sétány 1/c, Budapest 1117, Hungary

6 The Golden Triangle Asian Elephant Foundation (GTAEF), Chiang Saen, Chiang Rai, Thailand

7 Wildlife Conservation Society, Oxford, UK

8 Biodiversity Conservation and Ecosystem Management, School of Life Sciences and Bioengineering, Nelson Mandela African Institution of Science and Technology, Arusha, Tanzania 